meeting attended by about 50 physicians of all grades, who concluded that the standards of care needed considerable improvement. It emerged that the guidelines were not widely used by the junior medical staff, and it was agreed that there should be a major effort to comply with the guidelines whenever possible and that a further audit should be carried out in one vear to assess whether this had been achieved. The resolve to improve the referral rate to the respiratory firm was reaffirmed at a subsequent joint meeting with some 40 local general practitioners who, after receiving the results confirmed that they would expect all asthmatic inpatients to be seen by a chest physician during their stay and for their outpatient follow up.

Our findings suggest that though the introduction of audit may have improved such processes as clerking and record keeping, ${ }^{1}$ it has resulted in relatively little specific improvement in clinical care. However, the use of a simple questionnaire which may be reliably used by an audit assistant has allowed us to follow the audit cycle for patients admitted with asthma, and we are now using the same methods to perform smaller and shorter studies for several other conditions, including some audits performed as medical student projects. Such audits commonly disclose that the guidelines and questionnaires themselves need substantial modification, and it is important, especially as there is likely to be a bias against the publication of failed audits, that the many groups of physicians in the
United Kingdom who are optimistically adopting similar methods are aware that useful audit results such as those presented here are not always as straightforward to achieve.

We thank Ms Jane Wadsworth for her statistical advice, and Dr Martin McNicol for his encouragement and help.

I Gabbay J, MCNicol MC, Spiby J, Davies SC, Layton AJ. What did audit achieve? Lessons from a preliminary evaluation of a year's medical audit. B.MF 1990;301:526-9

2 British Thoracic Association. Death from asthma in two regions of England. B.M. 1982;285:1251-5.

3 North West Thames Regional Health Authority. Standard mortality rates for arcuilable cases of death by district. Annual report on the health of the population-district tables 1988. London: North West Thames Regional Information Unit, 1989.

4 Averv $\mathrm{CH}$, March J, Brook RH. An assessment of the adequacy of self care by adult asthmatics. Fournal of Community Medicine 1980;5:167-80.

5 Reed S, Diggle S, Cushley MJ, Sleet RA, Tattersfield AE. Assessment and management of asthma in an accident and emergency department. Thorax 1985:40:897-902.

6 Rebuck AS, Read J. Assessment and management of severe asthma. Am $\mathcal{F}$ Med 1971;15:788-98.

7 Bucknall CE Moran F, Robertson C Stevenson RD. Differences in hospital asthma management. Lancet 1988; $1: 748-50$.

8 British Thoracic Society. Guidelines for management of asthma in adults: II acute severe asthma. B.MF 1990:301:797-800

9 Layton AJ. Making the most of audit workers. Health Service fournal $1990 ; 100: 1685$

10 Higgins RM, Cookson WOCM, Lane DJ, John SM, McCarthy GL, McCarthy ST. Cardiac arrhythmias caused by nebulised beta-agonist therapy. Lance $1987 ;$ ii: $863-4$

11 (jrant IWB. Guidelines for management of asthma. BMF 1990;301:1045.

\title{
Arcadia revisited: quality assurance in hospitals in The Netherlands
}

\section{Evert Reerink}

Of all the attributes of medical care the assurance of its quality is the least known. At best it is respected, but it is never loved and never popular. Scientific progress, medical research, eradication of disease, and alleviation of grief and sorrow continue to be the pinnacles of medical care. Accountability, openness, and empathy do not score highly. Yet these are equally traditional values of the medical profession that must be taught, disseminated, and, often, defended.

Medicine as it is practised is as much engrained in a country's culture and tradition as are, say, literature and the arts. If the intellectual and political climates are favourable to, or at least tolerant of, the development of arts and sciences, medical care will profit - and this holds true for quality assurance. The keys to the proper development of modern quality assurance are tolerance, common consent, and confidence. Conflict, mistrust, and competition are definitely counterproductive. Each country has the quality assurance system that befits its health care system.

\section{Dutch health care system}

In The Netherlands it seemed appropriate to hold physicians responsible for their professional work, and on this basis they claimed responsibility for the quality of their care, the ultimate consequence of which is to assess quality and, if necessary, improve it. Assessing and improving quality is relatively recent. In the 1960 s and early 1970s few professionals bothered. Around 1975, however, hospital doctors, united in their national specialists organisation, Landelijke Specialisten Vereniging, and perhaps triggered by the developments in the USA, where state organisations
(Professional Standards Review Organizations) had been established to look into the quality of medical care in hospitals, and by the realisation that the current methods of quality care assurance were hopelessly outdated, renewed the tenet that physicians must be responsible for their quality of work. The Landelijke Specialisten Vereniging also took the next step: though professing their responsibility, specialists also acknowledged their ignorance of how to conduct modern quality assurance. Help and support were necessary. ${ }^{1}$ The government fell in with the idea for this initiative, leaving professional quality assurance to the health professions and supporting the creation of $\mathrm{CBO}$, an organisation to help clinicians in their self imposed task of quality assurance. The government completed the so called tripod of quality assurance by declaring openly its non-interference in quality assurance in the health care sector and instead professed its commitment to the cause. It and subsequent governments were set on a course of diminished interference in health care, and the new proposal fell on fertile ground. However, all parties thought that something should be done about the perceived unattained benefit in medical care.

\section{Present problems in health care}

At that time the Dutch health care system, which had previously been in good shape, started to show several shortcomings. This was not unique: the health care system in The Netherlands had (and has) similar problems to those of health care systems in other developed countries. There is considerable similarity between the health care problems in The Netherlands 
and Britain: increasing health care costs, an uncontrollable influx of expensive and often potentially dangerous technology, an increasing number of industrial disputes involving salaried nurses and physicians working on a fee for service basis, often vociferous public indignation, increasing numbers of patient claims, and attacks on health care in the press. In medicine itself problems were perceived, such as a lack of effectiveness, courtesy, and information to patients; uninformative medical records; and unsatisfactory communication between professionals. It is also clear that the solutions to these problems are similar in both countries: to re-establish working relations between professionals and both the government and hospital management, increase collaboration between professions, introduce patients as equal partners in matters pertaining to their health and disease, stem the flood of mishaps, and generally improve the quality of care delivery. Still the question remains of how to go about this.

\section{Quality assurance}

In most of the issues above quality of care (or its lack) was the core of the problem and had to be addressed squarely. Although a support organisation had been created, it remained primarily the task of the professionals to improve their quality of work. Thus in the hospitals quality assurance committees were set up and programmes were designed to address the most obvious and prevalent problems with quality. By their nature these problems differed from hospital to hospital: from more than 1400 priority problems selected in 46 hospitals between 1977 and 1990 about a third were typically problems of effectiveness-doctors could achieve better outcomes and increase the benefit for their patients; a third could be called problems of efficiency-doctors could better make use of the existing resources; and the remaining third was a conglomerate of patient related problems and organisational and interpersonal problems (conflicts) that needed to be solved among professionals. The same divisions pertain to nursing and physiotherapy, which are two recent additions to hospital quality assurance targets.

\section{One basic method for assuring quality}

In The Netherlands the term health care quality assurance is preferred to terms indicating its separate elements, such as medical audit or nursing audit, reflecting willingness to break down interprofessional barriers and recognise health care as a joint venture in which many professionals participate and collaborate.

To make things clear to busy clinicians the method of quality assurance was introduced in the simplest of terms, and clinicians were presented with one basic methodological framework (figure). This problem solving method looks just like medical practice in its

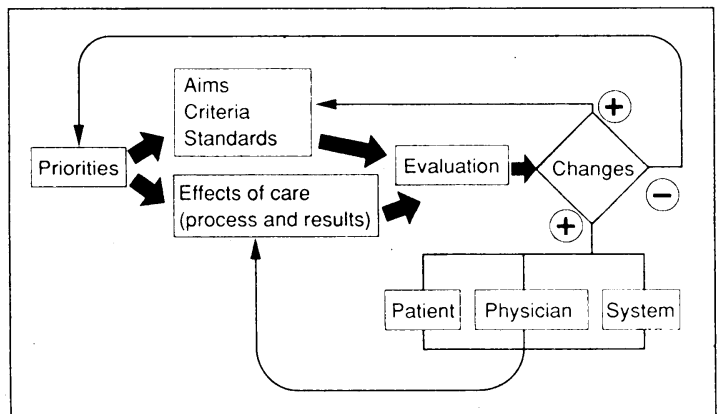

Steps in quality assurance process assessment and improvement constituents. With this framework it is easy to determine what the various tasks are, where a division of tasks is in order, and where the emphasis should be. It has been applied in all health care sectors where quality of care is a concern: since 1974 in a growing number of acute care hospitals; in general practice (since 1980 through a separate support organisation); in nursing (since 1984), physiotherapy (since 1988), and other paramedical services; and in future in mental health (from 1991) and occupational health. Nevertheless, the main focus up to now has been on hospital care.

\section{Practice of quality assurance}

In acute care hospitals and most university hospitals many quality assurance activities have been effected since the declaration of the Landelijke Specialisten Vereniging and the inception of CBO. Local quality assurance committees, which are often multidisciplinary, set their own programme to deal with their own problems of quality. ${ }^{2}$ In a few hospitals quality assurance professionals, mostly physicians, have joined the committees to alleviate their tasks. The table shows a sample of study topics.

\section{Sample problems for quality assurance activity in a general hospital}

Preoperative assessment in ASA-I^ patients

Prevention of decubitus (bed sores)

Accuracy of execution of dietary prescriptions Elimination of side effects after gentamicin treatment

Need for skull radiographs after skull trauma Deficient medical record keeping

Appropriateness of intravenous alimentation

Appropriateness of do not resuscitate policies Improved triage in the emergency department

^ASA-I = American Society of Anesthesiologists category I (otherwise healthy patients operated on for a minor ailment)

In keeping with the underlying thought of the quality assurance programme, consultant doctors are the mainstay of the job, being engaged in either running the programme (which generally takes one 90 minute planning and coordination meeting every three weeks) or working on parts of it, such as selecting priorities or setting criteria. The reports of studies of quality, which must include a full assessment and suggestions for improvement, are invariably discussed and approved in the full medical staff meeting. Large hospitals (with more than 500 beds) may manage eight to 10 topics a year; the smaller institutions have a more modest target of three to five topics.

Changes in practice may be observed, although this seems to take time. Studies in which, for example, the proper completion of the medical record has been investigated show that it may take many months before an appreciable change is detected. The need for behavioural change is noted much more commonly than the need for more education. ${ }^{3}$ In addition, it must be noted that the medical staff in a hospital, the body which in this quality assurance system is the final arbiter in medical quality issues, is a fairly recently established institution: in some hospitals the medical staff is not yet fully equipped to take the necessary educational and corrective measures expected of it. However, physicians are now more knowledgeable about quality assurance and appreciate that it is not the threatening activity which they had hitherto resisted. Quality assurance in nursing has been even more 
successful in implementing change, and the same holds true for other disciplines such as physiotherapy.

\section{Towards a national quality assurance policy}

The apparent success of quality assurance in hospitals has encouraged similar activities in other sectors within and outside hospitals, such as dentistry and pharmacy. A national policy was set in 1989 and renewed in 1990 in which health professionals, institutions, financiers, and the government participated. This led to the decision by the Ministry of Health not to introduce prescriptive legislation that might interfere with professional quality assurance matters. Instead it opts for supportive legislation that stimulates quality assurance in all branches of health care.

\section{Resource centre for quality assurance}

The existence of $\mathrm{CBO}$, the Utrecht based independent resource centre for quality assurance in hospitals, has triggered discussions on similar institutions in other countries. Invariably attempts were made to copy the centre but were followed by the admission that a resource centre is but one element in the tripod on which modern quality assurance is based, and that its foundation and functioning are highly dependent on suitable staff and stable funding. Yet in some European countries analogous organisations have been built up: in Belgium (Louvain), Germany (Kiel and Munich), Italy (Udine), France (Paris), and Spain (Barcelona and Madrid), often with the active support from The Netherlands. Even countries such as Australia, Malaysia, Canada, and the United States with their tradition of compulsory quality assurance have adopted the philosophy of assisting health care providers in setting up and maintaining voluntary quality assurance activities in hospitals. A recent project of the World
Bank aimed at instituting quality assurance in the general hospitals of Bangladesh will start with creating a resource centre in Dhaka, to support clinicians and nurses in executing their new task successfully.

\section{The future}

The introduction of quality assurance in any sector of health care should never be a single event, a solo action by an interested party; many more elements must be taken into account, acted on, and attuned to the common goal of improving the quality of health care delivery. Pertinent legislation; a positive attitude of health professionals, hospital management, and politicians; dealing with resistance to change; educating health care professionals and patients; and providing funds are the main elements of a whole fabric, of which the introduction and maintenance of quality assurance is only one part. ${ }^{4}$ Thus a resource centre, which can deal with all these issues simultaneously through expertise and networking, is the more necessary. Countries that worry about the quality of their hospital services might start with creating such an independent centre and enjoy the benefits it brings.

There is unanimity in The Netherlands about the course of quality assurance for the coming years. But all parties acknowledge the difficulties entailed in upholding the fabric as it has been developed in the past 10 years. The Arcadian landscape depicted here has suffered from passing storm clouds in the recent past (with industrial action by physicians), and it might easily acquire permanent darker textures.

1 Reerink, E. Improving the quality of hospital services in The Netherlands. The role of CBO; the National Organization for Quality Assurance in the Netherlands. Quality Assurance in Health Care 1990;2:146-54.

2 Van der Voorde F, Van der Snoek JA, Reerink E. A quality assurance study of the barium enema. Quality Review Bulletin 1981;6:10-13.

3 Rittersma J, Casparie AF, Reerink E. Patient information and patien preparation in orthognatic surgery. I Maxillofacial Surg 1980;8:206-9.

4 Dutch Issue: Quality Assurance in The Netherlands. Australian Clinical Review $1987 ; 7: 1-54$

\section{News and Information}

$\mathrm{G}$ eneral practitioners in the Oxford region seldom ask or record routine questions about lifestyle (British Journal of General Practice 1991;41:140-3). For example, a history of smoking was obtained by two thirds of them and a history of drinking by only a quarter; smoking was recorded by nearly half and occupation by only $23 \cdot 5 \%$. Enthusiasm expressed for preventive health care in the new contract is unlikely to make up for a startling lack of practice statistics.

$\mathrm{A}^{\mathrm{n}}$ from across the border, recording of five risk factors for cardiovascular disease in a random sample of 100 patients each from 24 practices in north east Scotland gave the following figures: blood pressure $68 \%$, smoking $47 \%$, weight $31 \%$, alcohol $20 \%$, and height 13\% (British Fournal of General Practice 1991;41:144-6). A year later (did participants know they were to be audited again?) records had improved, though not always significantly.

$\mathrm{T}$ he widespread and in some cases mandatory use of occurrence screening (what we would call adverse reactions) in the United States as a measure of quality assurance is increasingly being questioned (Fournal of the American Medical Association 1991;265:1977-81). It is retrospective, inefficient (in one study only $1 \cdot 2 \%$ of over 1200 occurrences were attributable to medical care), labour intensive, and very costly - and in general it measures safety not quality.
A well known figure in quality assurance, Richard Wentzel, makes an appeal for a "medical care perestroika," in which academic clinical epidemiologists and hospital managers would share evaluation of existing provision, monitor new programmes, implement acceptable guidelines, and establish costs (Archives of Internal Medicine 1991;151:653-4). Perhaps one of Britain's beleaguered medical schools could take up the challenge?

$\mathrm{O}$ ne hundred and twelve anaesthetists were asked to rate appropriateness of care for 21 matched pairs of cases in which an adverse outcome was labelled either temporary or permanent (Fournal of the American Medical Association 1991;265:1957-60). Ratings fell by 31\% when outcome was changed from temporary to permanent and rose by $28 \%$ when changed from permanent to temporary. Severity of outcome seems to influence judgment of quality of care.

A hough $98 \%$ of a random sample of 300 general practitioners believed that it was their job to deal with problems of overweight, only a fraction knew simple facts about its prevalence and dietary recommendations (British Fournal of General Practice 1991;41:147-50). They tended to use one to one advice and leaflets rather than group therapy, family involvement, and behavioural methods, which are said to be more effective. Most found the work unrewarding; perhaps one partner could develop a special skill in weight problems? 